\title{
COVID-I 9 and Tuberculosis Coinfection: A Report of Two Cases
}

\author{
Mradul Kumar Daga', Naresh Kumar' ${ }^{2}$, Govind Mawari ${ }^{3}$, Siddharth Chand ${ }^{4}$, ] Aarthi ${ }^{5}$, \\ Raghu RV ${ }^{6}, \underline{\text { Karan Sachdeva }}{ }^{7}$ \\ ${ }^{1}$ Director Professor, ${ }^{4,5,6}$ Resident, ${ }^{7}$ Department of Medicine, Maulana Azad Medical College, New Delhi, India. \\ ${ }^{2}$ Professor of Medicine \& Head, Pulmonary Medicine, Maulana Azad Medical College, New Delhi, India. \\ ${ }^{3}$ Scientist - C, Centre for Occupational and Environmental Health, Maulana Azad Medical College, New Delhi, India. \\ DOI: https://doi.org/10.24321/2454.325X.202103
}

\section{I $\quad \mathbf{N} \quad \mathbf{F} \quad \mathbf{O}$}

\section{Corresponding Author:}

Mradul Kumar Daga, Department of Medicine, Maulana Azad Medical College, New Delhi, India. E-mail Id:

drmraduldaga@gmail.com

Orcid Id:

https://orcid.org/0000-0001-7774-7602

How to cite this article:

Daga MK, Kumar N, Mawari G, Chand S, Aarthi J, Raghu RV, Sachdeva K. COVID-19 and Tuberculosis Coinfection: A Report of Two Cases. Int J Preven Curat Comm Med. 2021;7(1):20-24.

Date of Submission: 2021-02-27

Date of Acceptance: 2021-03-25

\section{$\begin{array}{llllllllllll}\mathbf{A} & \mathbf{B} & \mathbf{S} & \mathbf{T} & \mathbf{R} & \mathbf{A} & \mathbf{C} & \mathbf{T}\end{array}$}

COVID-19 and its sequelae are primarily known to affect the respiratory system. However, it can have varied manifestations affecting other systems as well. COVID-19 can lead to reactivation of tuberculosis which can have unusual extrapulmonary presentations as well. Coinfection of COVID-19 and tuberculosis is a risk factor for poor outcome. Here, we describe a series of two cases of COVID-19 with tuberculosis. In the first case, a patient who had apparently recovered from COVID-19 presented only a week later with polyserositis, and ultimately was diagnosed to be a case of disseminated tuberculosis. In the second case, the patient presented with COVID-19 and TB together. Clinicians must be aware and vigilant for this coinfection and complication in COVID-19 recovered patients even if they were of mild/ asymptomatic category.

Keywords: COVID-19, Tuberculosis, Coinfection, Post-COVID

\section{Introduction}

COVID-19, caused by severe acute respiratory syndrome coronavirus 2 (SARS-CoV-2), has resulted in a serious crisis in the global health system and has the case fatality rate as high as 26 per cent in hospitalised patients. ${ }^{1}$ Presence of coinfection is one of the important aspects which affects the clinical outcome in these patients. Lansbury et al. in their meta-analysis of thirty studies reported a bacterial coinfection in about seven per cent of hospitalised COVID-19 patients. ${ }^{2}$ In the Indian context, the presence of Tuberculosis (TB) should always be kept in mind as a coinfection because of the very high prevalence of TB. Tadolini et al. published a cohort of 49 patients with coinfection from eight countries. ${ }^{3}$ Motta et al. described a cohort of 69 patients in Italy with findings suggestive of higher mortality than expected in cases where advanced forms of TB frequently occurred and were caused by drug-resistant strains of $M$. tuberculosis. ${ }^{4}$ Similar case reports of TB and coinfection with COVID-19 has been reported from India also. ${ }^{5}$ Here, we present two cases of SARS-CoV-2 with reactivation of TB.

\section{Case Presentation}

\section{Case I}

A 48-year-old male presented with complaints of fever for 5 days along with a sore throat. The patient was advised RT-PCR for SARS-CoV-2 in view of the ongoing pandemic. His report was positive and the patient was advised home quarantine as he was only mildly symptomatic and was maintaining saturation. The patient was given antipyretics and vitamin supplementation for this duration. The patient 
got repeat RT-PCR done after 12 days which was negative and he was declared recovered from COVID-19. However, after one week, the patient again started developing lowgrade fever $\left(99-100^{\circ} \mathrm{F}\right)$, abdominal distention, and shortness of breath. On examination, he had a blood pressure of $110 / 70 \mathrm{mmHg}$, pulse rate of $88 / \mathrm{min}$, respiratory rate of $20 /$ min and $\mathrm{SpO}_{2}$ of $96 \%$ on room air. Air entry was absent in right infrascapular and infraaxillary area. The abdomen was distended suggestive of ascites.

The patient had anaemia with haemoglobin of $9.0 \mathrm{~g} /$ dl. Rest of the blood picture, kidney function tests, and liver function tests were normal. This time his RT-PCR for COVID was negative. ECG showed sinus rhythm. Chest X-ray was suggestive of right pleural effusion (Figure 1). The ultrasound of the abdomen was suggestive of gross ascites with mesenteric thickening throughout the abdomen and no features suggestive of chronic liver disease or kidney disease were seen. The ascitic fluid analysis revealed an exudative picture (460 cells, $80 \%$ mononuclear, $20 \%$ polymorph; sugar $42 \mathrm{mg} / \mathrm{dL}$, protein $4.8 \mathrm{~g} / \mathrm{dL}$ ). ADA in ascetic fluid was $34 \mathrm{IU} / \mathrm{L}$. Pleural fluid analysis showed similar findings (300 cells, $90 \%$ mononuclear, $10 \%$ polymorph; sugar $115 \mathrm{mg} / \mathrm{dL}$, protein $5.9 \mathrm{~g} / \mathrm{dL}$ ). ADA in pleural fluid was $37 \mathrm{IU} / \mathrm{L}$. Malignant cells or AFB positive cells were not seen in ascitic or pleural fluid. CECT chest and abdomen was done which was suggestive of tuberculosis (Figure 2). 2D echo was done which revealed mild pericardial effusion (Figure 3). Tuberculin sensitivity test (TST) was positive with induration of $15 \mathrm{~mm}$. Based on the clinical findings and report of TST, the patient was started on first-line antitubercular therapy (ATT). The patient improved significantly on regular treatment with ATT and is currently asymptomatic after 1 month of starting ATT.

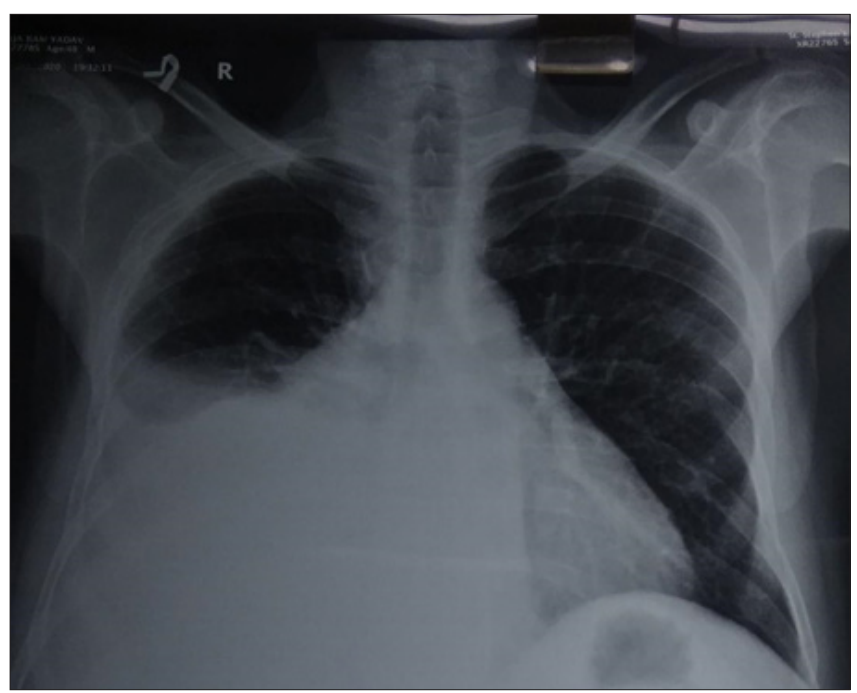

Figure I.Chest X-ray PA View showing Right-sided Pleural Effusion

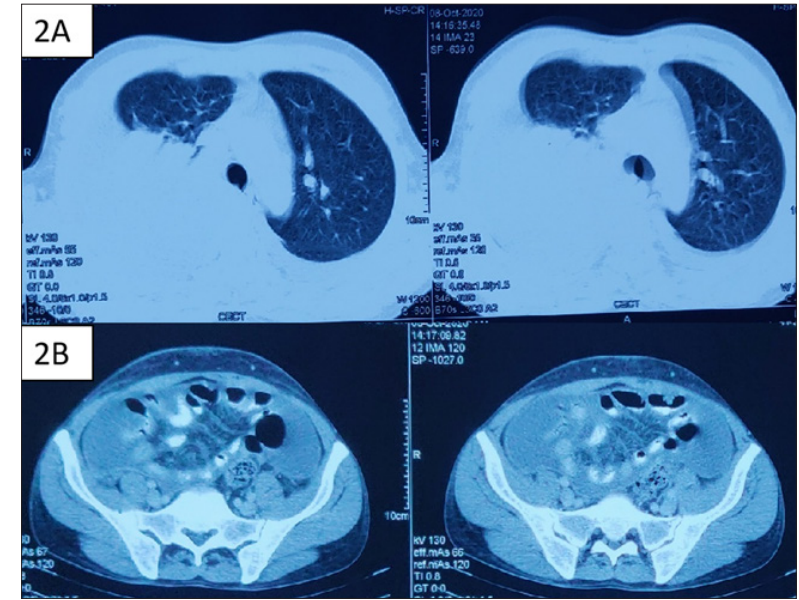

Figure 2.CECT Chest and Abdomen. (2A).Bilateral Pleural Effusion with Ascites. (2B). Mild Diffuse Smooth Peritoneal Thickening along with Thickened Heterogenous Omentum

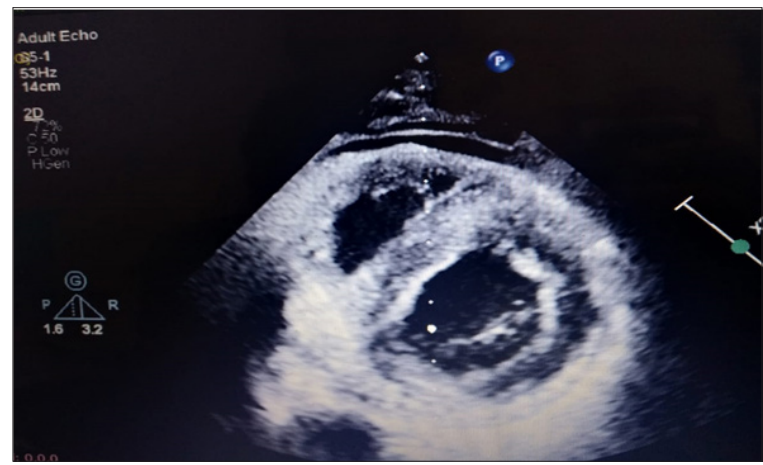

Figure 3.2D Echo showing Bilateral Pleural Effusion with Mild Pericardial Effusion with Normal Left Ventricular Systolic Function and No Evidence of Tamponade

\section{Case 2}

A 54-year-old man with a history of pulmonary TB since 15 years and known comorbidity of post tubercular sequelae, chronic obstructive pulmonary disease, and dilated cardiomyopathy on regular treatment was admitted to our hospital. He presented with complaints of fever, cough (nonproductive), and shortness of breath on exertion for the last 3 days. He had been diagnosed with COVID-19 based on a positive RT-PCR report. At the time of the presentation, his BP was $108 / 60 \mathrm{mmHg}$, pulse rate was $120 / \mathrm{min}$, respiratory rate was $30 / \mathrm{min}$ and $\mathrm{SpO}_{2}$ was $85 \%$ on room air which improved to $96 \%$ with $10 \mathrm{~L}$ oxygen via non-rebreather mask. Chest X-ray showed confluent and discrete nodular opacities in bilateral lung fields and fibro-bronchiectatic changes (Figure 4). Laboratory abnormalities included slight leukocytosis with a neutrophilic predominance and raised IL6- $71.3 \mathrm{pg} / \mathrm{mL}$ (Table 1 ). He was managed with IV antibiotics, remdesivir, and oxygen supplementation. As he 
did not have sputum production, sputum for AFB/ CBNAAT could not be done. CECT chest, done next, was suggestive of reactivation of TB (Figure 5.A,B,C). Antitubercular therapy was added. However, his condition deteriorated rapidly and he succumbed to the illness on day three.

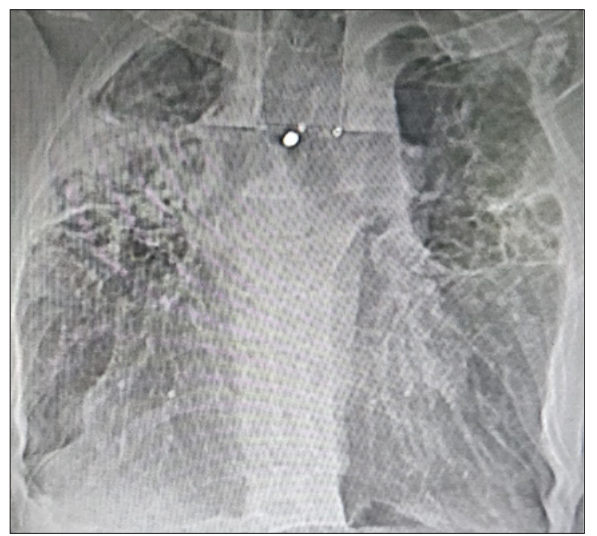

Figure 4.Chest X-ray PA View: Few Confluent and Discrete Nodular Opacities seen in Right Upper, Middle, and Lower Zone with Areas of Breakdown. Fibrous and Fibro-bronchiectatic Change seen in Bilateral Upper and Middle Zone with Pulled up Hilum and Volume Loss in Right Upper Zone

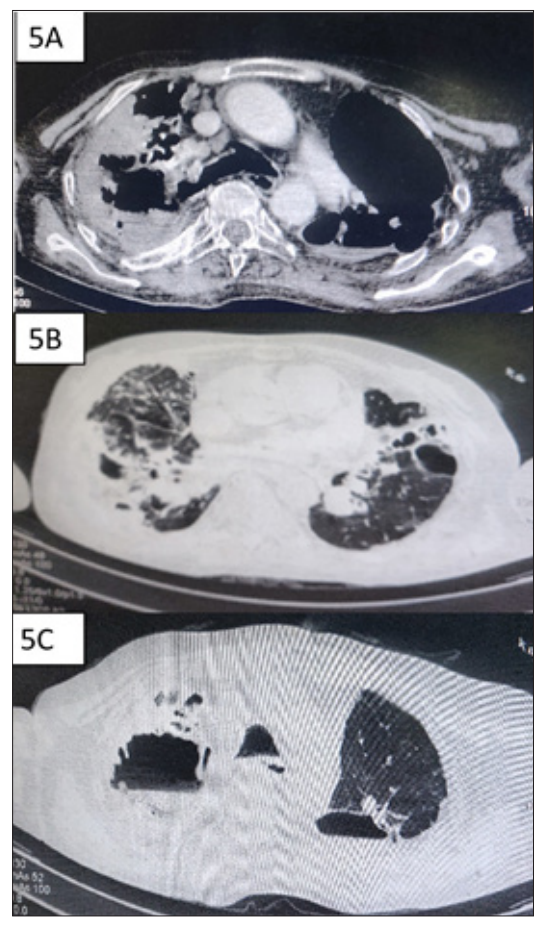

Figure 5.CECT Chest. (5A). Multiple Discrete Subcentremetric Lymph Nodes seen in Right Paratracheal and Subcarinal Location. Multiple Reticulonodular Opacities seen in both Lung Fields. (5B).CECT Chest: Multiple Areas of Opacities with Fibro-bronchiectatic changes. (5C).CECT Chest: Multiple Thin-walled Cavities in Bilateral Upper Lobes, and few Cavities showing Air Fluid Levels within
Table I.Investigations of the Patient

\begin{tabular}{|c|c|}
\hline Parameter & Value \\
\hline $\mathrm{Hb}$ & $12.9 \mathrm{~g} / \mathrm{dL}$ \\
\hline TLC & $12750 / \mathrm{mm}^{3}$ \\
\hline DLC & P88 L10 \\
\hline Platelets & $2.07 / \mathrm{mm}^{3}$ \\
\hline D-dimer & $557 \mathrm{ng} / \mathrm{mL}$ \\
\hline IL6 & $71.3 \mathrm{pg} / \mathrm{mL}$ \\
\hline PCT & $2.24 \mathrm{ng} / \mathrm{mL}$ \\
\hline
\end{tabular}

\section{Discussion}

The symptoms of COVID-19 caused by SARS-CoV-2 consist primarily of the respiratory system. Fever, myalgia, sore throat, and shortness of breath are some of the common findings. ${ }^{6}$ Gastrointestinal symptoms such as anorexia, and diarrhoea have also been described in COVID-19. ${ }^{7}$ The common finding as detected on CT chest in COVID is bilateral lobular consolidation and bilateral groundglass opacity. ${ }^{6}$ Although, pleural effusion and pericardial effusion are uncommon, they may be seen with disease progression. ${ }^{8}$ However, ascites and polyserositis have not been documented in COVID-19 and its sequelae.

This coinfection of TB and COVID-19 may be very relevant for countries with a high burden of TB. The complexity of identifying an association between the two may be due to multiple factors like an already existing high burden of TB, use of immunosuppressant drugs in COVID treatment protocol, and their similar presentation. It has also been postulated that a viral infection may activate dormant TB. ${ }^{9}$ A coinfection may be of greater concern because of the risk of increased mortality in view of dual infection and a huge impact on multiple systems in the country. As rightly pointed out by Kumar et al., physicians should be mindful of coinfection with TB, due to similar clinical presentation, otherwise TB may be overlooked in view of COVID positivity. ${ }^{5}$ Physicians attending to COVID-19 patients should always suspect and rule out TB in cases where- $i$ ) there is a history of tuberculosis in the past, ii) X-ray is suggestive of upper lobe involvement, iii) symptoms are present for more than 2 weeks. Finally, to find any association between the two, more cohort studies will be needed in the near future.

COVID-19 has caused a serious global health crisis even though almost four out of five patients are either asymptomatic or present with only mild symptoms. ${ }^{10}$ These patients are mostly managed in home isolation and are declared to have recovered roughly in two weeks. However, persistent symptoms have been described in patients of COVID-19. In a study of 143 patients from Italy, $87 \%$ of the 
patients reported symptoms in follow up. A large number of patients reported fatigue and shortness of breath. ${ }^{11} \mathrm{~A}$ systemic follow up has been warranted to monitor the development of pulmonary fibrosis as a COVID-19 sequelae.

Latent TB and reactivation of TB have to be kept in mind in India where the incidence of TB is very high. ${ }^{12}$ It has already been postulated that viral infection reactivates dormant TB. ${ }^{9}$ Coinfection of TB with COVID-19 is a major clinical challenge due to their similar presentation with respiratory symptoms. However, TB can also present with extrapulmonary symptoms as in the first case mentioned above. It is generally believed that TB protects against developing a severe form of COVID. ${ }^{13}$ This is why the study on BCG vaccination in preventing the development of COVID-19 is ongoing. The ACTIVATE (NCT03296423) trial has shown that recent BCG vaccination in the elderly (> 65 years) protected them against new infections. It was demonstrated that incidence of new infections after BCG vaccination was $25 \%$ and after placebo vaccination was $42.3 \%$, with most of the protection being against respiratory tract infections. ${ }^{14}$

\section{Conclusion}

COVID-19 can lead to reactivation of tuberculosis. Hence, reactivation of latent TB/ post-primary TB also needs to be considered when respiratory and other symptoms do not resolve in a specified time or reappear in post-COVID patients, especially in India where the prevalence of TB is so high. The follow up of post-COVID patients needs to be done vigilantly even in asymptomatic or mild cases.

\section{Conflicts of Interest: None}

\section{References}

1. Docherty $A B$, Harrison EM, Green CA, Hardwick HE, Pius R, Norman L, Holden KA, Read JM, Dondelinger F, Carson G, Merson L, Lee J, Plotkin D, Sigfrid L, Halpin S, Jackson C, Gamble C, Horby PW, Nguyen-Van-Tam JS, Ho A, Russell CD, Dunning J, Openshaw PJ, Baillie JK, Semple MG, ISARIC4C Investigators. Features of 20133 UK patients in hospital with COVID-19 using the ISARIC WHO Clinical Characterisation Protocol: prospective observational cohort study. BMJ. 2020;369:m1985. [PubMed] [Google Scholar]

2. Lansbury L, Lim B, Baskaran V, Lim WS. Co-infections in people with COVID-19: a systematic review and meta-analysis. J Infect. 2020;81(2):266-75. [PubMed] [Google Scholar]

3. Tadolini M, Codecasa LR, García-García JM, Blanc FX, Borisov S, Alffenaar JW, Andrejak C, Bachez P, Bart PA, Belilovski E, Landivar JC, Centis R, D’Ambrosio L, SouzaGalvao MLD, Dominguez-Castalleno A, Dourmane $S$, Jachym MF, Froissart A, Giacomet V, Goletti D, Grard S, Gualano G, Izadifar A, Du DL, Royo MM, Mazza-Stalder
J, Motta I, Ong CWM, Palmieri F, Riviere F, Rodrigo T, Silva DR, Sanchez-Montalva A, Saporiti M, Scarpellini P, Schlemmer F, Spanevello A, Sumarokova E, Tabernero E, Tambyah PA, Tiberi S, Torre A, Visca D, Murguiondo MZ, Sotgiu G, Migliori GB. Active tuberculosis, sequelae and COVID-19 co-infection: first cohort of 49 cases. Eur Respir J. 2020;56(1):2001398. [PubMed] [Google Scholar]

4. Motta I, Centis R, D’Ambrosio L, Garcia-Garcia JM, Goletti D, Gualano G, Lipani F, Palmieri F, Sanchez-Montalva A, Pontali E, Sotgiu G, Spanevello A, Stochino C, Tabernero E, Tadolini M, van den Boom M, Villa S, Visca D, Migliori GB. Tuberculosis, COVID-19 and migrants: Preliminary analysis of deaths occurring in 69 patients from two cohorts. Pulmonology. 2020;26(4):233-40. [PubMed] [Google Scholar]

5. Kumar R, Bhattacharya B, Meena V, Soneja M, Wig N. COVID-19 and TB co-infection - 'Finishing touch" in perfect recipe to 'severity' or 'death'. J Infect. 2020;81(3):e39-e40. [Google Scholar]

6. Huang C, Wang Y, Li X, Ren L, Zhao J, Hu Y, Zhang L, Fan G, Xu J, Gu X, Cheng Z, Yu T, Xia J, Wei Y, Wu W, Xie X, Yin W, Li H, Liu M, Xiao Y, Gao H, Guo L, Xie J, Wang G, Jiang R, Gao Z, Jin Q, Wang J, Cao B. Clinical features of patients infected with 2019 novel coronavirus in Wuhan, China. The Lancet. 2020 Feb;395(10223):497506. [Google Scholar]

7. Cheung KS, Hung IFN, Chan PPY, Lung KC, Tso E, Liu R, Ng YY, Chu MY, Chung TWH, Tam AR, Yip CCY, Leung $\mathrm{KH}$, Fung AYF, Zhang RR, Lin Y, Cheng HM, Zhang AJX, To KKW, Chan KH, Yuen KY, Leung WK. Gastrointestinal Manifestations of SARS-CoV-2 Infection and Virus Load in Fecal Samples From a Hong Kong Cohort: Systematic Review and Meta-analysis. Gastroenterology. 2020 Jul;159(1):81-95. [PubMed] [Google Scholar]

8. Salehi S, Abedi A, Balakrishnan S, Gholamrezanezhad A. Coronavirus Disease 2019 (COVID-19): A Systematic Review of Imaging Findings in 919 Patients. Am J Roentgenol. 2020 Jul;215(1):87-93. [PubMed] [Google Scholar]

9. Pathak L, Gayan S, Pal B, Talukdar J, Bhuyan S, Sandhya S. Coronavirus activates a stem cell-mediated defense mechanism that accelerates activation of dormant tuberculosis: implications for the COVID-19 pandemic. bioRxiv. 2020 May 6.

10. Wu Z, McGoogan JM. Characteristics of and Important Lessons From the Coronavirus Disease 2019 (COVID-19) Outbreak in China: Summary of a Report of 72314 Cases From the Chinese Center for Disease Control and Prevention. JAMA. 2020 Apr 7;323(13):1239-42. [PubMed] [Google Scholar]

11. Carfi A, Bernabei R, Landi F, for the Gemelli Against COVID-19 Post-Acute Care Study Group. Persistent 
Symptoms in Patients After Acute COVID-19. JAMA. 2020 Aug 11;324(6):603-5. [PubMed] [Google Scholar]

12. Pai M, Daftary A, Satyanarayana S. TB control: challenges and opportunities for India. Trans R Soc Trop Med Hyg. 2016 Mar;110(3):158-60. [PubMed] [Google Scholar]

13. Gupta PK. New disease old vaccine: Is recombinant BCG vaccine an answer for COVID-19? Cell Immunol. 2020 Oct;356:104187. [PubMed] [Google Scholar]

14. Gonzalez-Perez M, Sanchez-Tarjuelo R, Shor B, NistalVillan E, Ochando J. The BCG Vaccine for COVID-19: First Verdict and Future Directions. Front Immunol. 2021;12:632478. [PubMed] [Google Scholar] 